\title{
Study on the Xiangxian Council in Chinese Rural Governance in the Post-poverty Era
}

\author{
Ziyang Wang * \\ Department of Law and Political Science, North China Electric Power University (Baoding), Hebei, \\ 071066, China \\ *821066287@qq.com
}

\begin{abstract}
At present, Chinese society is in the stage of a decisive victory in building a moderately prosperous society in all respects. By 2020, all the existing impoverished counties and people in China will exit the ranks of poverty. As China enters the Post-poverty era, the issue of rural governance will become the key to a sustainable poverty alleviation in rural areas. As a new type of social organization, Xiangxian councils play an important role in rural governance. This research studied the existing problems of the Xiangxian Council in rural governance to promote Xiangxian's participation and practice in rural governance.
\end{abstract}

Keywords: Rural Governance; Xiangxian Councils; Post-poverty Era.

\section{Introduction}

In recent years, traditional governance resources are becoming more and more important. Therefore, an increasing number of local governments have re-incorporated social subjects into social governance, actively supporting and cultivating a wide range of social organizations with rural elites as the core. These rural elites participate in rural governance and have established a large number of entities, of which is the Xiangxian council.

\section{The Practical Dilemma of the Xiangxian Council in Rural Governance}

\subsection{Imperfect Supervision and Management Mechanism}

The development of the Xiangxian council in most areas is still immature and lacks restraint, so even tyrant-type rural elites have appeared in a small part of the area. Such Xiangxian councils can't play an active role but have become the local villain in the countryside. The existence of these phenomena is resulted from the lack of perfection of the working and operating mechanism of the Xiangxian council, and the absence of corresponding external supervision and internal management mechanisms to regulate the work of the Xiangxian council and restrict the power of the Xiangxian council. Therefore, the work effectiveness and the restraint management of the Xiangxian council is weak, and there is no way to concentrate its efforts to play its active role.

\subsection{Lack of Attention and Support from the Grassroots Government}

Some grassroots governments have not provided a functioning activity platform for the Xiangxian councils, let alone constructing a welfare guarantee and incentive mechanism for them. Such situation directly leads to the lack of opportunities and guarantees for the Xiangxian council to carry out activities, and has greatly hindered the development of the Xiangxian Council indirectly.

\subsection{Acting Beyond Authority Resulted from Unclear Positioning}

The inherent nature and characteristics of the Xiangxian council determined its auxiliary status. In rural governance, it needs to follow the leadership of Cunliang Wei (village party branch and village committee) and assist them in better exerting rural governance. However, because of the unclear position in rural governance, many Xiangxian councils don't have a good understanding of their auxiliary position. The phenomenon of councils overstepping on behalf of others often occurs, which directly badly affects the work of Cunliang Wei and grassroots governments. 
Volume 14 (2021)

\subsection{Shortage of Rural Elites with the Enthusiasm of Construction}

Due to the lack of a corresponding operating mechanism, especially an incentive and guarantee mechanism for the rural elite groups, they feel that returning to their hometown to make investments lacks actual utility. And the development of the rural elite organization is immature and lacks due cohesion, resulting in some rural elites losing enthusiasm in returning hometown to participating in rural governance. This is what caused the shortage of talents in rural revitalization.

\subsection{Ignorance of the Cultivation of Rural Culture and Ethics}

At present, the Chinese rural society is experiencing the impact of industrialization and urbanization. Rural social construction and management go together with the construction of rural customs, civilization and the exploration of new ways of rebuilding rural values. Modern democracy and scientific concepts are required in this process of transformation. When the Xiangxian council participates in rural governance, due to the villagers' insufficient understanding of the Xiangxian council and the complex social and cultural factors in the countryside, everyone pays too much attention to its support for economic development while ignoring equally important cultural development.

\section{Some Suggestions for Rural Governance in the Post-poverty Era}

\subsection{Suggestions for Grassroots Governments}

Coordinate and allocate resources rationally. Rural elites often carry economic resources returning hometown, which can effectively promote rural economic development. Township governments with Cunliang Wei should allocate these resources reasonably on the basis of evaluating the actual local situation. Pay attention to the utilization of technical resources to promote the development and optimize the structure of rural industries.

The township government is the commander-in-chief of coordinating the overall development of the village. In order to promote rural construction, it is necessary to open more channels for the return of the villagers. At the same time, the township government should let rural elites have a sense of satisfaction and gain in every sacrifice and organize activities between rural elites regularly so that they can be firmly united and truly devote to their hometown.

At present, the function orientation of the Xiangxian council is not clear enough, and often overlaps with that of the grassroots government and Cunliang Wei. The grassroots government should, according to different habits and customs of different regions, issue norms related to the Xiangxian council, providing strong institutional guidance and legal protection. However, the internal operation mode should be independently decided by the Xiangxian council itself. The grassroots government should not intervene excessively in case of giving it too much administrative function.

\subsection{Some Suggestions for Cunliang Wei}

Form a mutual division of labor between Cunliang Wei and the Xiangxian council. As an important supplement to Cunliang Wei, the Xiangxian Council's main responsibilities are to assist in the mediation of neighborhood disputes, the development of public welfare, and the self-government of villagers. Therefore, Cunliang Wei should clarify the division of powers with the Xiangxian council so that these subjects can each perfectly perform their duties. The duty of social construction of the village should be delegated to the Xiangxain council, and the major issues should be decided by Cunliang Wei. If there is duplication of responsibilities, a negotiation should be carried out to build consensus of all the villagers.

Whether it is the Cunliang Wei or the Xiangxian council, the common goal of both is to promote the implementation of the rural revitalization strategy. In order to stimulate the vitality of the village and strengthen and innovate the management of the village, the communication and cooperation between the two sides is extremely important. Based on the fact that the operation mode, rules and 
regulations of the Xiangxian councils have not yet formed a mature system, the exploration of its internal working methods will inevitably be controversial. The Cunliang Wei plays a role in resolving the conflicts within the council. Through communication, Cunliang Wei can clarify the fundamental direction of rural construction for the Xiangxian council to understand the ideas of the rural elites and promote the formation of consensus.

Improve the overall quality of the Xiangxian council team and select elites from different fields. Cunliang Wei and the grassroots governments should seriously inspect and select the council members who can truly serve the people. Only in this way can the council's coordination and organization capabilities be enhanced to deal with the complex rural governance environment.

\subsection{Some Suggestions for Xiangxain Councils}

The leadership of the party branch is the top priority for rural elites to participate in rural governance and to achieve good governance in the village. Only when the work of the Xiangxian council is placed under the leadership of the party branch can the participation of the rural elites achieve the role of supplement instead of replacement. Therefore, in the process of participating in rural governance, the Xiangxian council must always adhere to the leadership of the rural grassroots party organizations, keep up with the pace of the Communist Party of China, and stand in an auxiliary position to participate in rural governance.

The Xiangxian council has many resources that can be contributed to all aspects of rural governance. This calls for a strict internal mechanism to regulate various work of the Xiangxian council and strengthen the organization and mobilization. A supervision system that takes account of both internal and external considerations should be established to ensure the sound development of the Xiangxian council. Construct a scientific and concrete work system to achieve well-founded and effective goal in daily capital investment and application, industrial project construction, and settlement of villagers' conflicts. Adhere to the decision-making mechanism of democratic participation, promote the implementation of democratic elections, democratic supervision, democratic management and democratic decision-making.

In the Post-poverty era, we are paying growing attention to the important leading role of Xiangxian culture in the construction of rural customs and civilization. To be more specific, the rural elite members of the Xiangxian council have a demonstration role. Therefore, the cultural values promoted by the Xiangxian council through various activities are more easily accepted by the villagers, and the excellent traditional culture can also be promoted. Therefore, the Xiangxian council must persist in the development of the Xiangxian culture, deepen and promote the excellent connotation of rural culture, make more down-to-earth cultural activities and cultivate the new style of rural civilization.

\section{References}

[1] Yuanyuan Xu. Poverty Governance in the Post-poverty Alleviation Era: Trends, Challenges and Ideas [J]. National Governance,2020,(01):18-21.

[2] Changjian Li, Yonghai Yang. The dilemma and response of new Xiangxian participating in the resolution of conflicts and disputes--Based on field investigations in H Town, Henan Province [J]. Agricultural Economics and Management,2019,(04):73-84.

[3] Youxin Lang, Pin Zhang, Keyang Xiao. New Xiangxian and the Effectiveness of Rural Governance-Based on the Experience of Dongheng Village, Luoshe Town, Deqing County, Zhejiang Province [J]. Journal of Zhejiang Provincial Party School,2017,33(04):16-24.

[4] Min Sun. The Organizational Characteristics and Governance Mechanism of the Xiangxian Council-Based on the Investigation of the Xiangxian Council in Qingyuan City [J]. Journal of Hunan Agricultural University (Social Science) | J Hunan Agric Univ (Soc Sci),2016,17(06):49-55.

[5] He Cai, Hui Hu, Zhaoan Zhou. The Xiangxian Council: A New Exploration of Village Social Governance-Local Experience from D Village, Y City, Western Guangdong [J]. Academia Bimestrie, 2016,(03):4654 . 